\title{
IMPACT BETWEEN BUILDINGS DURING EARTHQUAKES
}

\author{
A. J. Carr' and P. J. Moss'
}

This paper was presented at the NZNSEE Technical Conference, Taupo, March 1994

\begin{abstract}
A numerical study of the parameters affecting the impact between adjacent buildings subjected to seismic excitation has been carried out in an endeavour to quantify the relative importance of the structural parameters.

A two-dimensional inelastic dynamic analysis program was used to model various combinations of adjacent framed structures subjected to ground accelerograms and where the frames are assumed to be separated by distances sufficiently small as to permit contact. Collisions were modelled using special contact elements which will transmit forces when the specified gap has been closed.

It will be shown that where there are adjoining frames are of different heights, large increases in response are observed in the upper part of the taller frame. Pounding can also amplify the effects of localised changes in stiffness and strength up the frame, producing member demands greatly in excess of the normal design values.
\end{abstract}

\section{INTRODUCTION}

During earthquakes, adjacent buildings of different heights and masses are most likely to sway out of phase with one another and lateral collisions or "pounding" can occur if the separation between the buildings is not great enough. While pounding has been identified as a potential hazard for some time, even to the extent that separation between buildings is covered in the various building codes, it is only in recent years that the problem has received substantial attention. this is largely due to the increase in structural and non-structural damage that has occurred around the world, particularly in the 1985 Mexico earthquake where pounding was observed in over $40 \%$ of collapsed or severely damaged buildings and attributed to be the major cause of failure in over $15 \%$. Other earthquakes where building pounding has occurred include San Fernando (1971), Nicaragua (1972), Philippines (1976), Romania (1977), Central Greece (1981) and Loma Prieta (1989).

One avenue of research is the analytical study of the dynamics of pounding. There are numerous references in this field, though most are concerned with the general vibro-impact problem rather than the pounding problem. The main purpose of these studies is to provide a better understanding of the macro-behaviour under pounding and to study the non-linear contact problem in detail. Generally, these studies have used single degree-of-freedom (SDOF) models of each building and the impacts have been modelled using elements having linear elastic or linear visco-elastic properties. Parameters studied have included variation in gap size, excitation frequency and amplitude, energy dissipation, relative masses, impact element stiffness and damping properties and strength levels.

\footnotetext{
${ }^{1}$ University of Canterbury, Christchurch, New Zealand (Fellow)
}

Typical of some of this research is the work of Davis [1] who used harmonic excitation and considered the cases of both stationary and moving rigid boundaries. Spectra of impact velocity were presented for a range of model parameters covering both single and multiple impacts per cycle. These spectra were found to be characterised by a strong peak near a period equal to one half the natural period of a similar nonimpacting oscillator. An exact analytical solution for the special case of infinite impact stiffness was also presented, and used, to provide insight into the required separation for the reduction or elimination of pounding.

Another direction of current research uses MDOF systems to model actual structures in order to capture their impact response. Parameters studied have included variation in relative building heights, masses and foundation properties, input excitation frequency, impact element stiffness, and gap size. Maison, Kasai et al [2-5] have developed a line of research with accompanying computer software which attempts to provide the practising engineer with the analytical tools for the analysis of pounding problems. In the program, SLAM, the building of interest vibrates laterally and collides with an adjacent building that is assumed to be rigid. In SLAM2, pounding occurs between two flexible frames, each having 3 DOF per floor level. Impacts are modelled using visco-elastic members but can only occur at the top of the lower building. Parameter studies have covered the effect of relative mass, impact member stiffness and damping, ańd gap size. They have also presented a method for estimating the required building separation to preclude pounding, this being based on a modal analysis.

A further topic of pounding research is concerned with damage mitigation. These studies cover a wide range of alternatives for existing and planned structures. Solutions for the former include the use of energy absorbing materials in the gap between 
structures and rigidly connecting the two structures at some point to force them to respond as a single unit. Solutions for the latter include studies on the required separation to prevent pounding, locating floor levels of adjacent buildings at the same level and special design of the gravity load system to ensure integrity under pounding conditions.

More recently, Sinclair [6] has carried out studies of the response of adjacent buildings subjected to seismically induced pounding. A two-dimensional, inelastic, dynamic analysis program was used to model different combinations of adjacent frames and separated by distances insufficient to prevent contact. Collisions were modelled using special impact elements which developed compressive stiffness only after the specified separation had been exceeded.

Three case studies were selected in which various multi-storey frames were arranged in different configurations. These were then analysed for pounding at separations which ranged from zero to that required for no collision to occur. The buildings examined were steel and reinforced concrete moment-resisting frames of regular geometry. The configurations selected involved pounding between frames of different period, total

Six Storey Two Bay Frame

Member Numbering and Level Defunitions

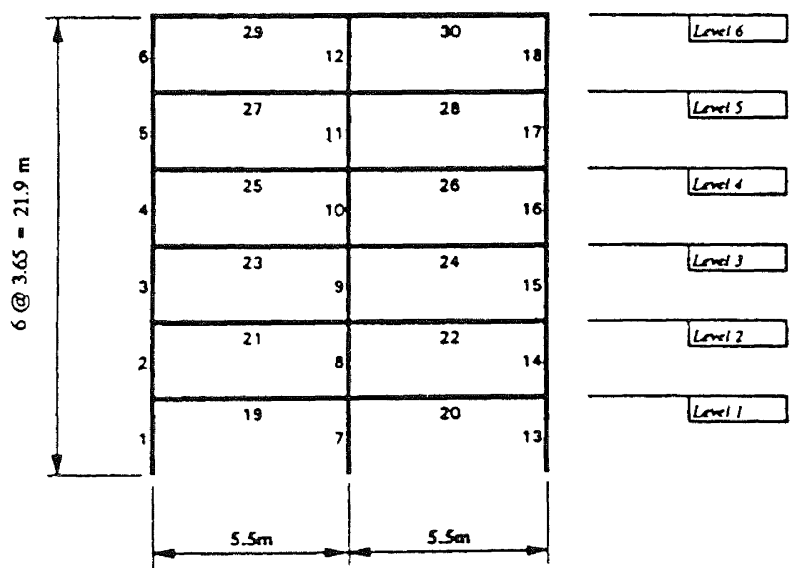

Twetve Storey Two Bay Frame Member Dimensions

\begin{tabular}{|l|c|c|}
\hline MEMBERS & LEVEL & DIMENSIONS $(\mathrm{mm})$ \\
\hline \multirow{2}{*}{ Beams } & 1.6 & $900 \times 400$ \\
& 7.8 & $850 \times 400$ \\
& $9-12$ & $800 \times 400$ \\
Exterior & 1.6 & $775 \times 500$ \\
Columns & 7.8 & $750 \times 500$ \\
& $9-12$ & $650 \times 500$ \\
miterior & 1.6 & $800 \times 800$ \\
Columns & 7.8 & $725 \times 725$ \\
& 912 & $675 \times 675$ \\
\hline
\end{tabular}

Figure $1 \quad$ The six and twelve storey frames used. height, and inter-storey height. High response increases were observed for both frames in all cases, particularly in the upper stories. Pounding between frames of different storey height was found to induce larger response increases than for the equal storey height case. Vibratory, design level earthquake excitations and artificial records generally caused sufficiently greater response increases than the impulsive maximum credible earthquakes such as the Pacoima Dam record.

The work reported in this paper is related to that carried out by Sinclair.

\section{STRUCTURES ANALYSED}

Two reinforced concrete frames, one of six stories and the other of twelve stories, were used for the analyses reported in this paper. These were the frames used by Thompson [7] and were originally designed by Jury [8] to the New Zealand Loadings Code, NZS4203, of the time. They correspond to framed structures in which all frames share equally in carrying the gravity and seismically induced loads. The columns of the twelve storey frame were subsequently redesigned by Paulay [9]

Six Storey Two Bay Frame Member Dimensions

\begin{tabular}{|l|c|c|}
\hline MEMBERS & LEVEI & DTMENSTONS (mm) \\
\hline Beams & $1-6$ & $600 \times 350$ \\
& $7-12$ & $550 \times 350$ \\
Exterior & $1-6$ & $500 \times 450$ \\
Columns & $7-12$ & $450 \times 450$ \\
Interior & $1-6$ & $550 \times 550$ \\
Columns & $7-12$ & $500 \times 500$ \\
\hline
\end{tabular}

Twetve Stony Two Bay Frame Member Numbering and Level Defuritions

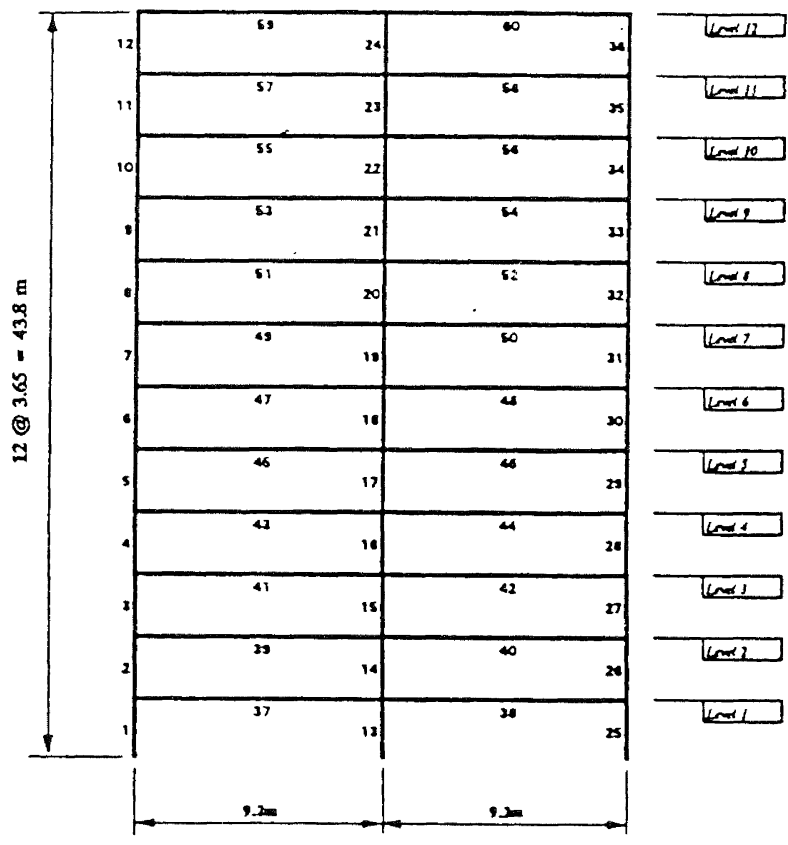


according to new data that indicated that their reinforcement ratios were rather high. These frames have been modelled extensively in previous research at the University of Canterbury and their behaviour is generally well understood. The frame configurations and member sizes are shown in Figure 1.

In converting the real pounding problem to a computer model, it was necessary to make a number of assumptions. The two adjacent multistorey frames were assumed to vibrate laterally such that collisions could occur if there insufficient clearance between the buildings. The collisions could occur only at the floor levels and could occur at any level. This was in contrast to the assumption made by many researchers that collisions would occur only at the top level. The collisions themselves were modelled using special impact-elements which used the Hertzian Contact hysteresis rule in conjunction with a truss member. The mass was lumped at the nodes and included both horizontal and vertical inertias; the rotational inertia was not modelled as this reduced the number of degrees of freedom in the model without significantly affecting the results. Constant modal damping of $5 \%$ was used [10].

\section{RESULTS}

Analyses carried out using the El Centro NS 1940 (corrected) earthquake record are reported in this paper. Further earthquake records are also being used with a view to confirming, or otherwise, the findings of Sinclair [6] that the "design level" earthquakes such as El Centro 1940, artificial earthquakes generated to match the design spectrum in NZS
4203:1992, and Hachinohe produce greater response increases than do the 'maximum credible' type earthquake records such as Parkfield 1966 and Pacoima Dam 1971.

\section{DISCUSSION}

\section{Overall Performance}

The results are not as dramatic as those reported by Sinclair [6] for his analyses of pounding between a six storey $\mathrm{RC}$ frame and an eighteen storey steel frame since the pounding is influenced both by the period difference between the two frames which allows out-of-phase motion to develop, and by the relative masses of the two frames.

In this study, the period ratio $\mathrm{T}_{12} / \mathrm{T}_{6}=1.94 / 0.89=2.18$ and the twelve storey frame has a mass that is twice that of the six storey frame. In Sinclair's study [6], two twelve storey frames had an equal storey mass but a maximum period ratio of 1.58 while a six storey RC frame and an eighteen storey steel frame had a relative mass of three and a period ratio of 3.60 .

\section{Frame Displacements}

Typical frame displacement envelopes are shown in Figure 2 for the cases of $1 \mathrm{~mm}$ gap and no pounding while the variation in the displacements at the top of the six and twelve storey frames are shown in Figure 3, along with the displacement of the sixth floor of the twelve storey frame. The sixth storey relative displacement time history is shown in Figure 4 along with the Total Impact Force (TIF).

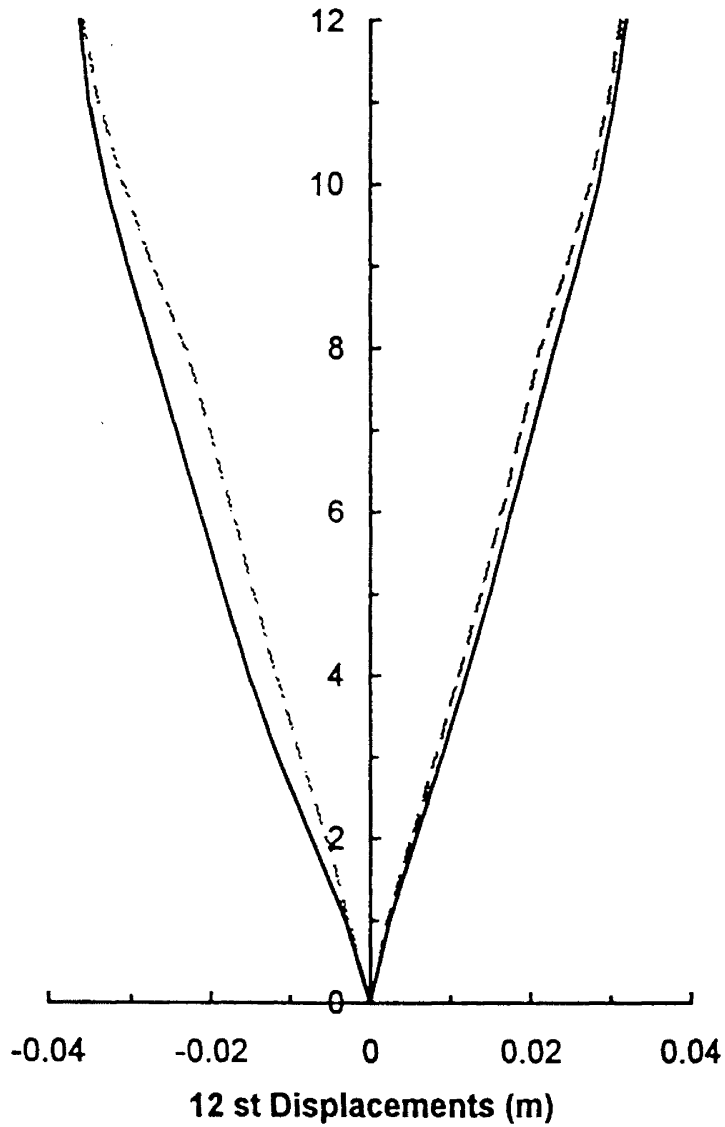

Figure 2 Variation in Storey Displacement with Storey and Gap Size. 

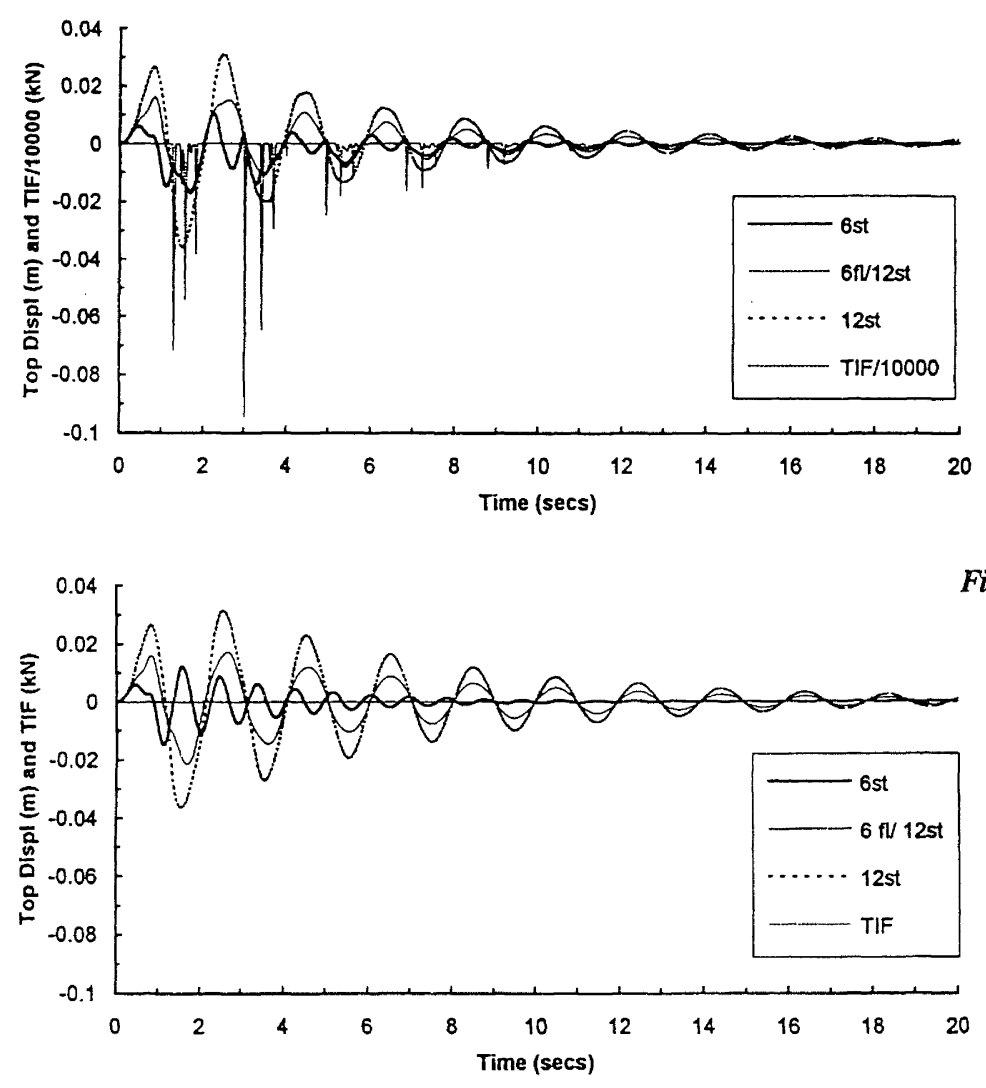

Figure 3 Top Displacement Time Histories for the pounding analysis of a six-storey $R C$ frame and a twelve-storey $R C$ frame subjected to El Centro 1940; (Top) Pounding (Gap = $1 \mathrm{~mm})$, (Bottom) No Pounding (Gap $=100 \mathrm{~mm})$
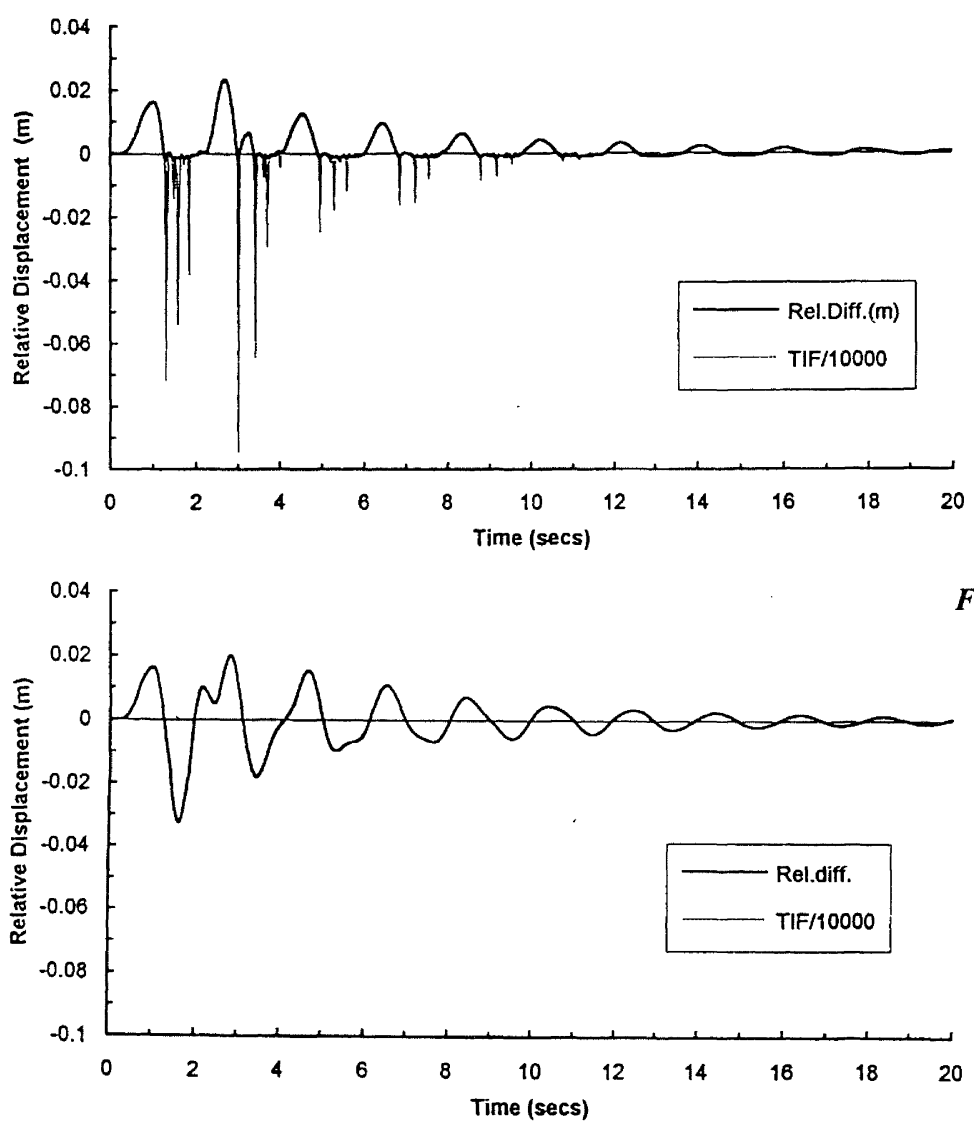

Figure 4 Relative Top Displacement Time Histories for the pounding analysis of a six-storey $R C$ frame and a twelve-storey $R C$ frame subjected to El Centro 1940; (Top) Gap = Imm, (Bottom) No Pounding (Gap $=100$ mm) 

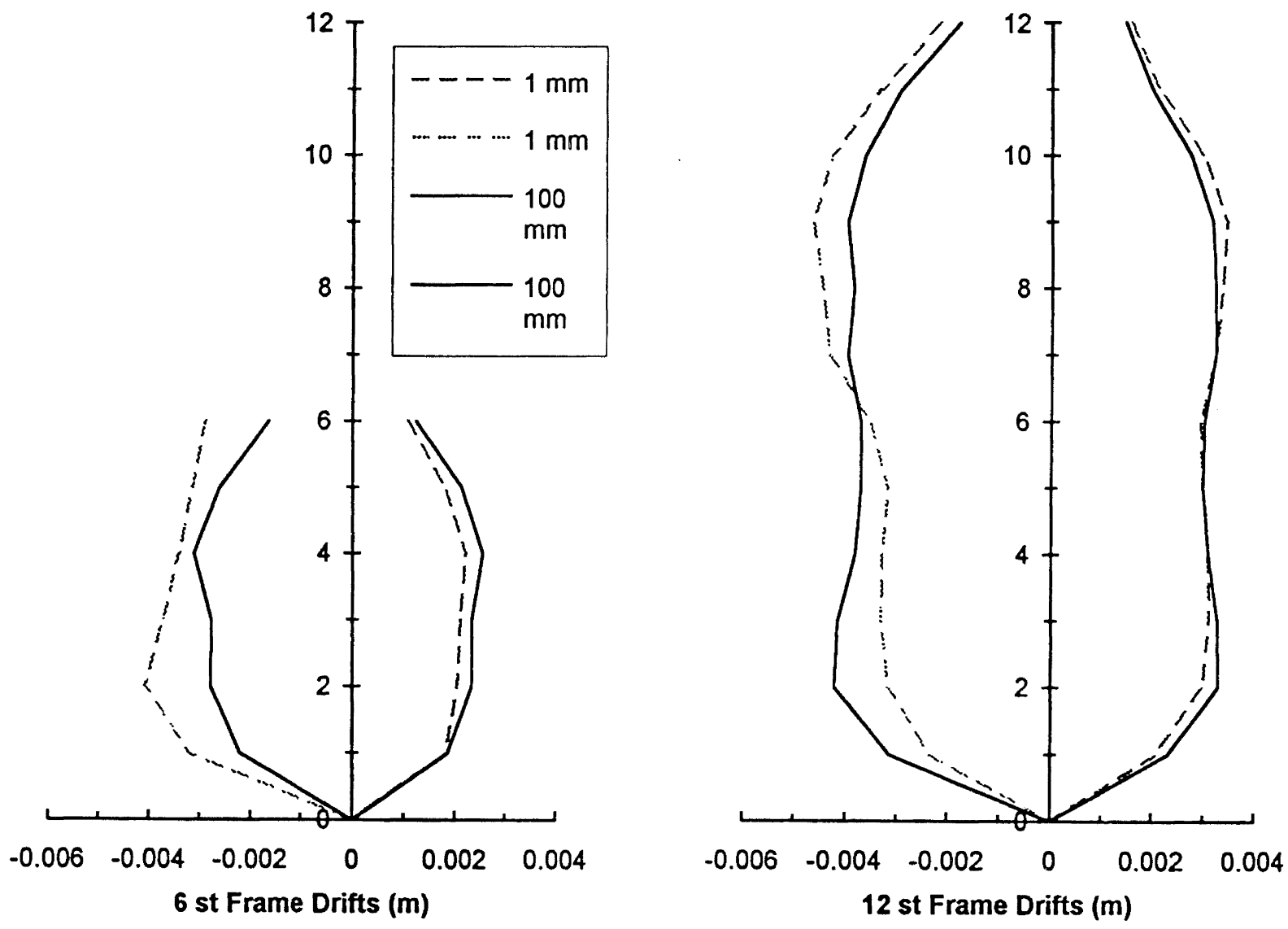

Figure 5 Storey Drift for pounding due to the El Centro 1940 earthquake record.

\section{Drifts}

The envelope of storey drifts is plotted in Figure 5. In general, the six storey frame experienced the larger drift increases since the response of the frame is low when pounding does not occur. The maximum response ratios (the ratio of response during pounding to the response with no pounding) are higher at the tops of both frames. The effect of pounding is for the drifts to be reduced in the lower stories of the twelve storey frame and increased in the top stories.

\section{Shears and Impact Forces}

A typical storey shear envelope is shown in Figure 6 while a typical base shear time history is shown in Figure 7 . While the six storey frame shows a slight change in the shear force in the top storey for a $1 \mathrm{~mm}$ gap, there is a very marked increase in shear at the sixth storey level for the twelve storey frame. When compared to the regular appearance of the storey shear envelopes for the case with no pounding, several features become apparent as explained by Sinclair [6]. The shear response modification caused by pounding can best be explained by separating the response into two parts. Firstly there are the shear forces due to the impacts that occur as the buildings impact on each other. These impacts generate short duration forces which may be up to twice the typical storey weight and produce shear waves that travel through the building in both horizontal and vertical directions.

The second part of the frame shear response is the change due to the altered displacement patterns. As Sinclair points out, the frame storey displacement envelopes are shifted away from each other by the impacts, resulting in larger positive and negative shears developing in the six and twelve storey frames respectively. The other case occurs when the twelve storey frame 'over-tops' the six storey frame. Here, there are three possible impact cases to consider along with two displacement cases [6].

The variation in maximum impact force with gap size is shown in Figure 8. It can be seen that the peak impact force always occurred at the top pounding level. Where pounding did occur in the lower levels, the consequences are reflected in the storey drifts as outlined earlier.

The prevalence of top storey only impact events is important from a modelling point of view. Maison et al [2-5], examined pounding in which the impacts occurred only at the top level. The results reported herein, along with those of Sinclair [6], that "this assumption is realistic when the adjacent frames possess either significant separation or height difference. However, when this is not the case, impacts between the lower levels of adjacent frames produce significant response increases and should therefore be included in the analysis to produce accurate results".

\section{CONCLUSIONS}

Where the adjacent frames are of different heights, the upper storey levels in the taller frame overtop the shorter frame during the impacts. This produces large response increases in the upper part of the taller frame. 

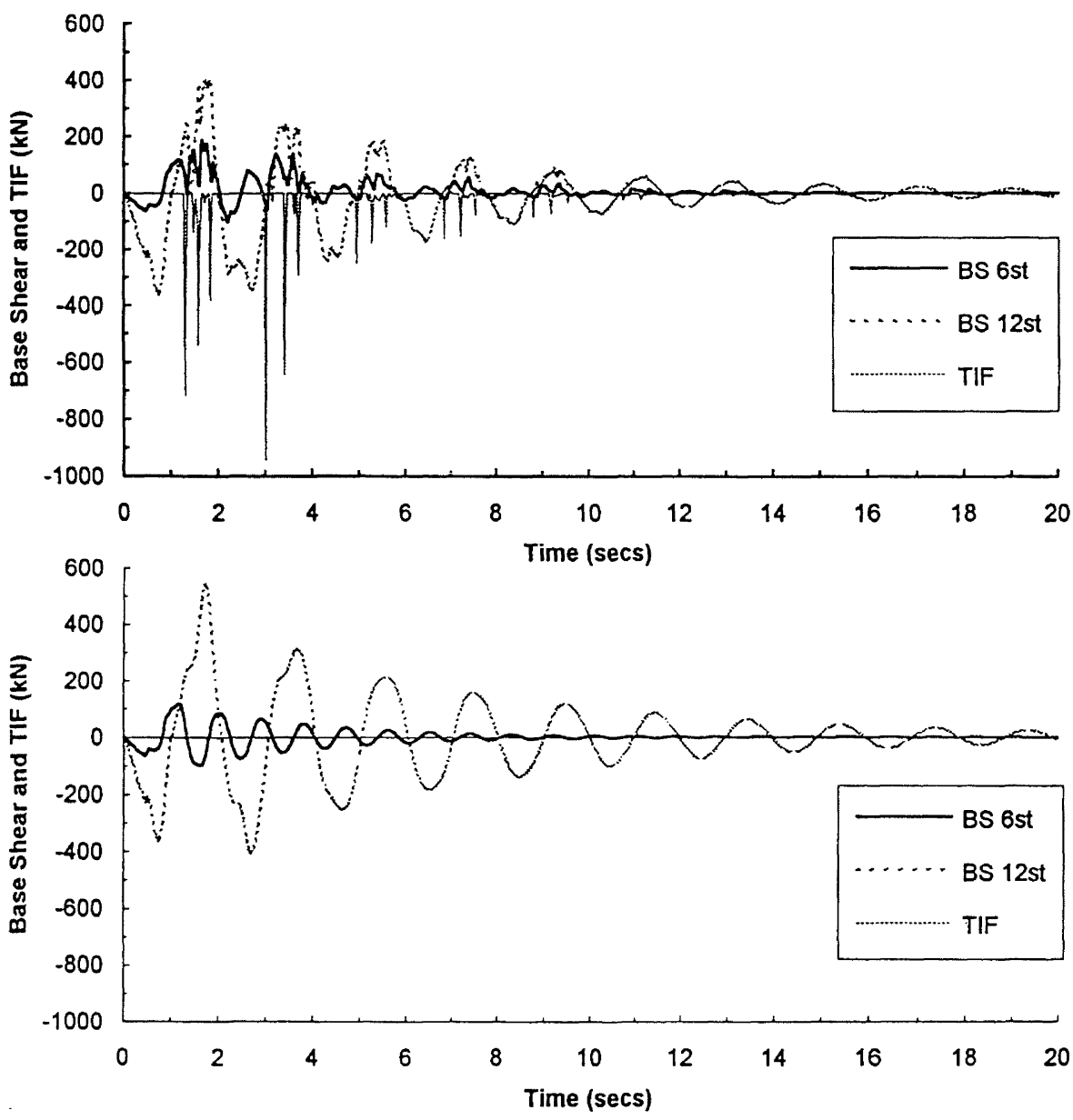

Figure 6 Base Shear Time Histories for the pounding analysis of a six storey RC frame and a twelve storey $R C$ frame subjected to El Centro 1940; (Top) Gap = Imm, (Bottom) No Pounding (Gap=100 $\mathrm{mm}$ )
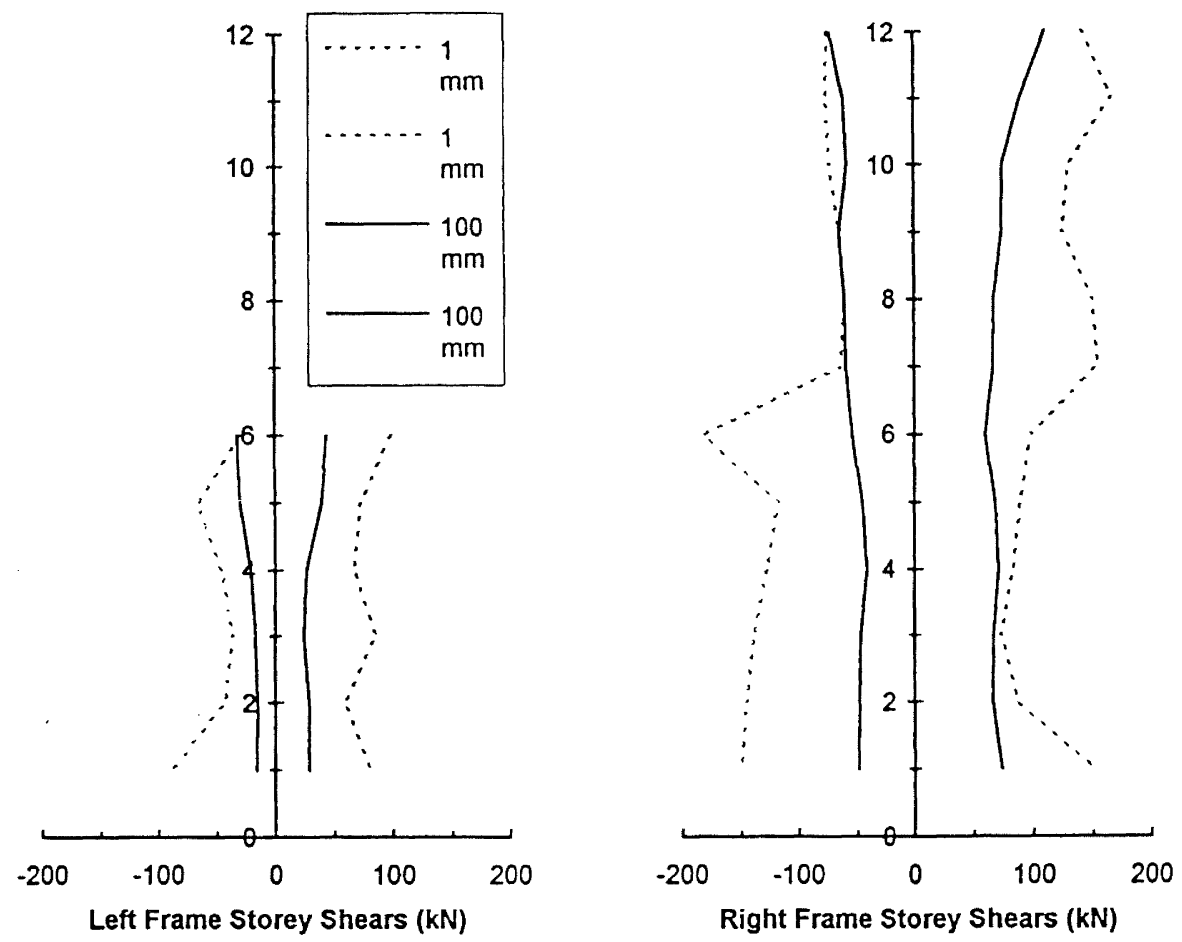

Figure $7 \quad$ Base Shear Time Histories for the pounding analysis of a six storey $R C$ frame and a twelve storey RC frame subjected to El Centro 1940; (Top) Gap = Imm, (Bottom) No Pounding (Gap=100 $\mathrm{mm}$ ) 


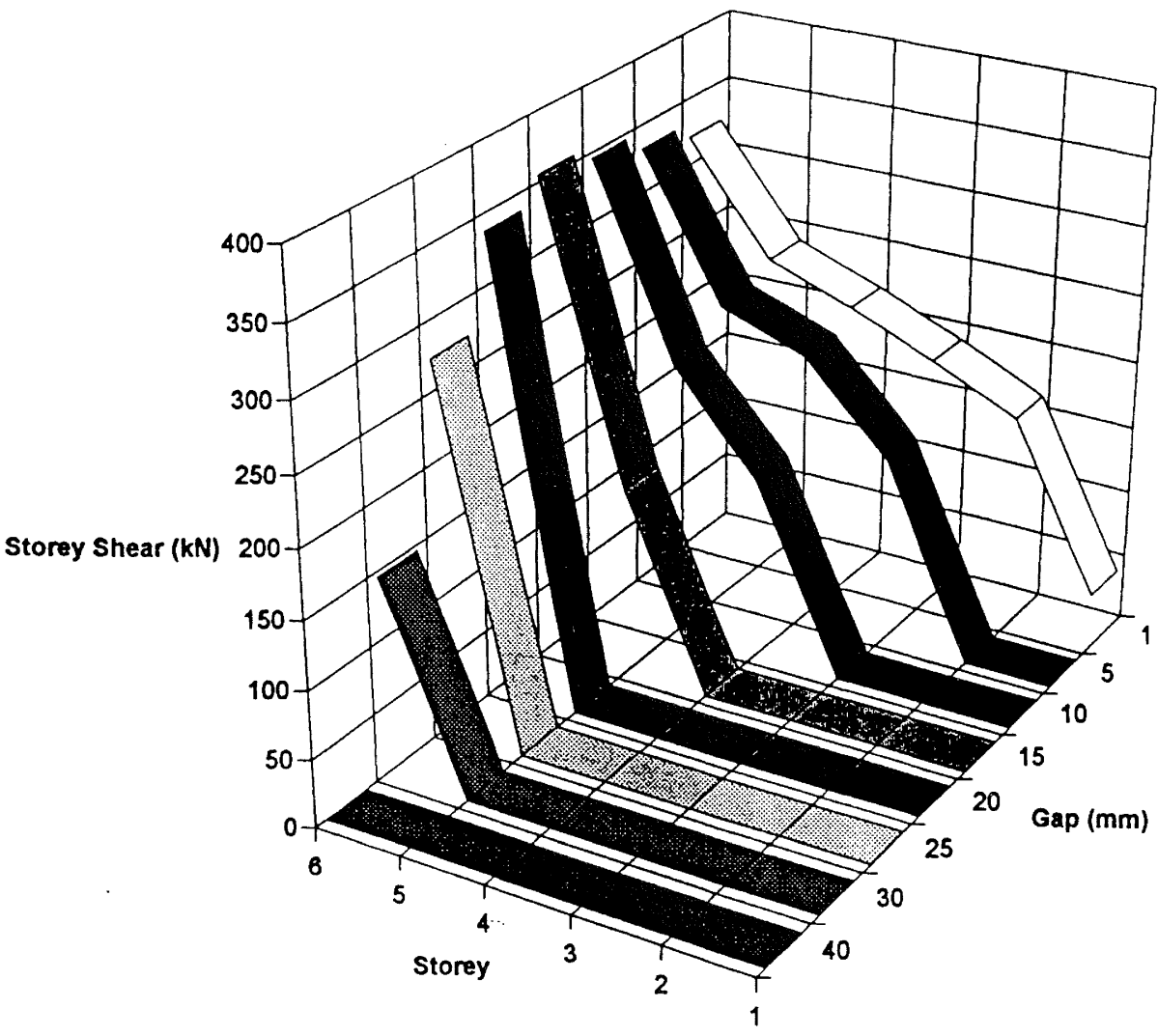

Figure $8 \quad$ Variation in Maximum Impact Force with gap size.

The storey and base shear time history plots for buildings subjected to pounding are more jagged and irregular than for the corresponding non pounding analysis. The importance for the appropriate design values of the transient peaks that can distort the maximum response envelopes has yet to be determined.

\section{REFERENCES}

1. Davis, R.O. 1992. Pounding of Buildings Modelled by an Impact Oscillator. Earthquake Engineering and Structural Dynamics. 21:253-274.

2. Maison, B.F. and Kasai,K. 1990. Analysis for a Type of Structural Pounding. J. Struct. Eng. 116(4):957-975.

3. Kasai, K., Maison, B.F. and Patel, D.J. 1990. An Earthquake Analysis for Buildings Subjected to a Type of Pounding. Proc. 4th U.S. National Conf. on Earthquake Engineering.

4. Maison, B.F. and Kasai,K. 1992. Dynamics of Pounding When Two Buildings Collide. Earthquake Engineering and Structural Dynamics 21:771-786.
5. Jeng, V., Kasai, K. and Maison, B.F. 1992. A Spectral Difference Method to Estimate Building Separations to Avoid Pounding. Earthquake Spectra 8(2).

6. Sinclair, K.M. 1993. The Response of Multistorey Frames to Seismic Pounding. M.E. Report, University of Canterbury.

7. Thompson, E.D. 1991. P-Delta Effects in Ductile Reinforced Concrete Frames Under Seismic Loading. M.E. Report, University of Canterbury, Christchurch.

8. Jury, R.D. 1978. Seismic Load Demands on Columns of Reinforced Concrete Multistorey Frames. Research Report, 78-12, Dept. of Civil Engineering, University of Canterbury.

9. Paulay, T 1979. Developments in the Design of Ductile Reinforced Concrete Frames. Proc. 2nd South Pacific Regional Conf. on Earthquake Engineering, Wellington.

10. Carr, A.J. and Moss, P.J. 1994. Structural Damping Models for Non-Linear Seismic Analysis. Proc. 1994 NZNSEE Conference. 